\section{MedienPädagogik}

www.medienpaed.com
Zeitschrift für

Theorie und Praxis

der Medienbildung

ISSN 1424-3636

\title{
A Brief History of the Lecture: A Multi-Media Analysis $^{1}$
}

\author{
Norm Friesen
}

\begin{abstract}
The lecture has been much maligned as a pedagogical form. It has been denigrated as a «hot medium» that has long been «superseded» by the cooler dialogical and televisual forms. Yet the lecture persists and even flourishes today in the form of the podcast, the TED Talk, Kahn Academy and the «smart» lecture hall (outfitted with audio, video and student feedback technologies). This persistence should lead us to re-evaluate both the lecture and the role of the media that have been related to it over time. This paper examines the lecture as a site of intersecting media, as "a site where differences between media are negotiated» as these media evolve (Franzel 2010). This study shows the lecture as bridging oral communication with writing and newer media technologies, rather than as being superseded by newer electronic and digital forms. The result is a remarkably adaptable and robust form that combines textual record and ephemeral event. It is that is capable of addressing a range of different demands and circumstances, both in terms of classroom pragmatics and more abstractly, of the circulation of knowledge itself. The Web, which brings multiple media together with new and established forms and genres, presents fertile grounds for the continuation and revitalization of the lecture as a dominant pedagogical form.
\end{abstract}

\section{Introduction}

In recent texts on online and classroom pedagogies, the lecture has been labelled as old-fashioned «chalk and talk», as mere information transmission. The lecturer herself characterized as an antiquated «sage on the stage»--to be replaced by an interactive, constructivist «guide on the side.» A look at what is currently privileged in everyday practice, however, tells a different story. Video and audio podcasts of talks or lectures are common, with TED Talks and Kahn Academy presentations being a staple for students, teachers and technologists. Lecture hall feedback devices (or clickers) are popular as teaching tools, and the lecture circuit remains a forum of choice for even the most ardent advocates of online education. In my experience, it is not unusual to attend a presentation, like the TED («Technology

1 This paper is a version of «The Lecture as a Transmedial Pedagogical Form: A Historical Analysis», originally published in Educational Researcher. 
Entertainment and Design») Talk «This is Bullshit [sic]» by Jeff Jarvis (2010), in which a lecturer takes to the podium only to decry lecturing and the lecture in general. These contradictions can be clarified (but not entirely eliminated) by taking a look at the lecture as a form or genre, and at the complexities of its history and its communicative and «mediatic» dynamics. Such an examination shows that the lecture is a pedagogical form that interconnects multiple media --originally, spoken and written word; later audio, image and video. And it does this in a way that both reflect and reinforce prevailing epistemologies, approaches to knowledge and its propagation. It is, as Sean Franzel says, illustrative of the «intermediality of academic instruction», providing "a site where differences between media are negotiated» as these media co-evolve (2010). ${ }^{2}$ The result is a remarkably adaptable and robust form that combines textual record and ephemeral event; and this form is capable of addressing a range of different demands and circumstances, both practical and epistemological. The Web, which brings together multiple media together with new and established forms and genres presents fertile grounds for the continuation and revitalization of the lecture as a dominant form. I begin this paper with examples of conventional critiques of the lecture, followed by a broad overview of its history in Western educational contexts. I conclude by discussing ongoing vitality and adaptability of the lecture today, and by explaining how it points to a broader, mediatic understanding of practices and technologies in education.

A forceful yet representative critique of the lecture is found in Diana Laurillard's Rethinking University Teaching (1993/2001), in which she evaluates a broad range of educational forms and media in terms of their systemic, informational functions. Laurillard labels the lecture, along with print, video and DVD as «discursive» or «narrative» media, and she expresses a widely-held view in saying that its informational function is one of transmission. Like a print run or a video broadcast, the lecture, she maintains, works to disseminate information to its audience. It is representative of «non-interactive ... linear presentational media» that are above all associated with a "transmission model of education» $(91,93)$. However, unlike other narrative or presentational media, the lecture is singled out by Laurillard and others as profoundly defective, inefficient and outmoded. It is, she asserts, "a very unreliable way of transferring the lecturer's knowledge to the student's notes», suited only to "what is elegant or pleasing» rather than what is "difficult and complex» (94). Laurillard and others critique the lecture as a kind of atavistic throwback to «narrative form of the ancient oral cultures», representing a kind of

2 This paper was inspired by Sean Franzel's presentation, «The Lecture: A Case Study in the Intermediality of Academic Instruction», given April 102010 at Media Transatlantic: Media Theory in North America and German-Speaking Europe. See the conference program http://www.mediatrans.ca /final_conference_program.pdf for the abstract of Franzel's talk, and http://www.mediatrans.ca /Sean_B_Franzel.html for an audio and video recording of the same. 
«residual orality» in an era in which text is the dominant and most efficient medium (Brent 2005, n. p.; Jones 2007, 398). Laurillard goes so far as to say that such residual practices should be insufficient for any university that sees itself as «not enfeebled by tradition»:

Why aren't lectures scrapped as a teaching method? If we forget the eight hundred years of university tradition that legitimises them, and imagine starting afresh with the problem of how to enable a large percentage of the population to understand difficult and complex ideas, I doubt that lectures will immediately spring to mind as the obvious solution. (93; see also King 1993)

The survival of the lecture to the present day, in other words, cannot be explained in terms of the transmission of knowledge, for there are many more powerful and effective ways to do this, as Laurillard makes clear. Its endurance is not due to its efficacy as a solution to any pressing educational problem; instead, Laurillard insists, it can be explained only in terms of an enfeebling «eight hundred years of university tradition» (93).

In this paper, I argue that the centrality of the lecture over 800 years of university life is not due to historical inertia, but arises from its ability to reinforce rather than enfeeble academic practices and priorities.

\section{The Lecture as Cultural Preservation}

Laurillard and a variety of others - including Marshal McLuhan and Walter Ong - are correct in observing that the lecture is «rooted» in ancient oral cultures or «human orality» (Ong 1982; Brent 2005, n. p.; Jones 2007, 398). But I believe they are mistaken in the inference they draw from this observation: They conclude that it is a kind of «residual» communicative form that has long been replaced by textual and newer electronic media: «The sheer quantity of information conveyed by press-magazines-film-TV-radio», as McLuhan puts it, "far exceeds the quantity of information conveyed by school instruction and texts. This challenge has destroyed the monopoly of the book as a teaching aid» and has rendered the school «an obsolete detention home, a feudal dungeon» (1960a, 1; 1960b, 207). But the lecture, I argue, is more effectively understood as bridging oral communication with writing, rather than as being a purely spoken form that is superseded by textual, digital or other media technologies and other mediatic forms.

As Laurillard's remarks indicate, the history of the lecture goes back far before the advent of the printing press to the early middle ages. This is an era when even basic textual information was scarce, and when media were constituted and interrelated rather differently than today. The lecture played an indispensible 
role in education, but one very different from the informational functions of transmission or dissemination. Especially in the early middle ages, the capacities and resources for reading and writing were scarce and jealously guarded, the lecture was less about broadcasting knowledge than it was about rescuing a written cultural heritage from irretrievable loss and decay. (For example: Lucretius' epicurean classic, The Nature of Things, is a part of Western tradition because it was discovered by Poggio Bracciolini, an Italian scholar, who recognized the title from his reading of Cicero. He lent the manuscript to a friend, and it was later lost. But befor that occurred, his friend made a transcription, which then served as the basis for the more than fifty other copies that launched the text as an early modern classic.)

The medieval meaning of the word lecture is to read or read aloud (meanings reflected in the Latin root legere and in French and German cognates today), and that is precisely what a lecture was: a reading or dictation of selections of an authoritative text, most often the Bible or an ancient authority. Books were specifically designed to fit on a podium or cathedra as it was then called (Briggs and Burke 2009, 54). Books were also sometimes written in scripta continua, without spacing and punctuation, requiring vocalization in order to be deciphered. (Arabic writing and older forms of the Hebrew alphabet did not have ways of indicating vowels, mkng vclztn whl rdng ncssry.) As a result, personal, silent reading is believed to have been relatively rare. Public readings were a popular form of entertainment, and in attending lecture courses, one spoke of going to "hear» the corresponding «books» being read (see: Wieruszowski 190). In these senses, one could say that the act of reading was typically an act of lecturing (a «reading aloud»), and that a lecture was almost always a matter of reading. The two were functionally equivalent.

This was also a time when knowledge and truth were seen as having been passed from God to Adam, and (via Hermes Trismegistus, as some believed) to the present in the form of ancient texts. Teaching and learning were conceptualized as acts of «recovery» of this tradition rather than novel «discovery» of something radically new (Harbison, as cited in Eisenstein 1997, 123). Consequently, the lecturer could only serve as a kind of conduit for knowledge from the past, with his students (both were generally was a male) providing a way of reconciling contradiction and giving fuller meaning to these sources. The idea of speaking or extemporizing on one's own ideas was unknown, and in fact, the lecturer be fined for departing from a slavish dictation the text at hand (Eisenstein 1997, 524). Thus, the lecture or the sermon, as it was also known, was a site of slow oral dictation, careful memorization (Clarke 2006, 68-73) and painstaking note taking. 
Teaching in the medieval university involved different oral exercises and associated writing ... medieval students engaged in various kinds of notetaking from oral teaching, including making minor changes to a ready-made text brought into class, taking more or less sketchy reportationes of oral teaching delivered at higher than dictation speed, and copying out under dictation the full text of a course. ... large numbers of surviving manuscripts attest to the prevalence of full-text notes taken by students from dictation. ... (Blair 2008, 44, 46-47)

This note taking, however, was not just for personal reference and study; it could serve as a way of reproducing the texts themselves. Particularly in the early centuries of the development of the universities, "the simplest way of getting [books]... was for the teacher to dictate the texts to his pupils» (Hajnal 1954, as quoted in McLuhan $1962,95)$. The result is that «drifting texts and vanishing manuscripts», copied by students or monks effectively constituted the body of written information available to the culture. It was the task of educational institutions to preserve this vulnerable heritage "from one generation to the next», above all «by writing» (114). ${ }^{3}$

In the 1450's into this world of informational paucity, the printing press unleashed an era of relative informational abundance. As one account from the early modern period opines, through the printing press, texts were

multiplied, as now a book is reproduced many thousandfold. Therefore if one, two, three, ten or twenty are burnt or otherwise are given up, there are still very many additional others, so that a book is never totally lost... (Annonymous; see figure 1)

Naturally, this plenitude of printed information presented a challenge to the function of the lecture as a means of textual reproduction, as a site of dictation and verbatim note taking. Elizabeth Eisenstein reports that as books gradually become cheaper and more plentiful, lecturing professors were no longer unrivalled as a sources and masters of information and learning:

Gifted students no longer needed to sit at the feet of a given master in order to learn a language or academic skill. Instead, they could swiftly achieve mastery on their own, even by sneaking books past their tutors - as did the young would-be astronomer, Tycho Brahe. "Why should old men be preferred to their juniors now that it is possible for the young by diligent

3 I owe a special debt of gratitude to Emily Hutchison of Thompson Rivers University for her help with this discussion of the medieval lecture and student note-taking. 
study to acquire the same knowledge»? asked the author of a fifteenthcentury outline of history. (Eisenstein 2005, 38)

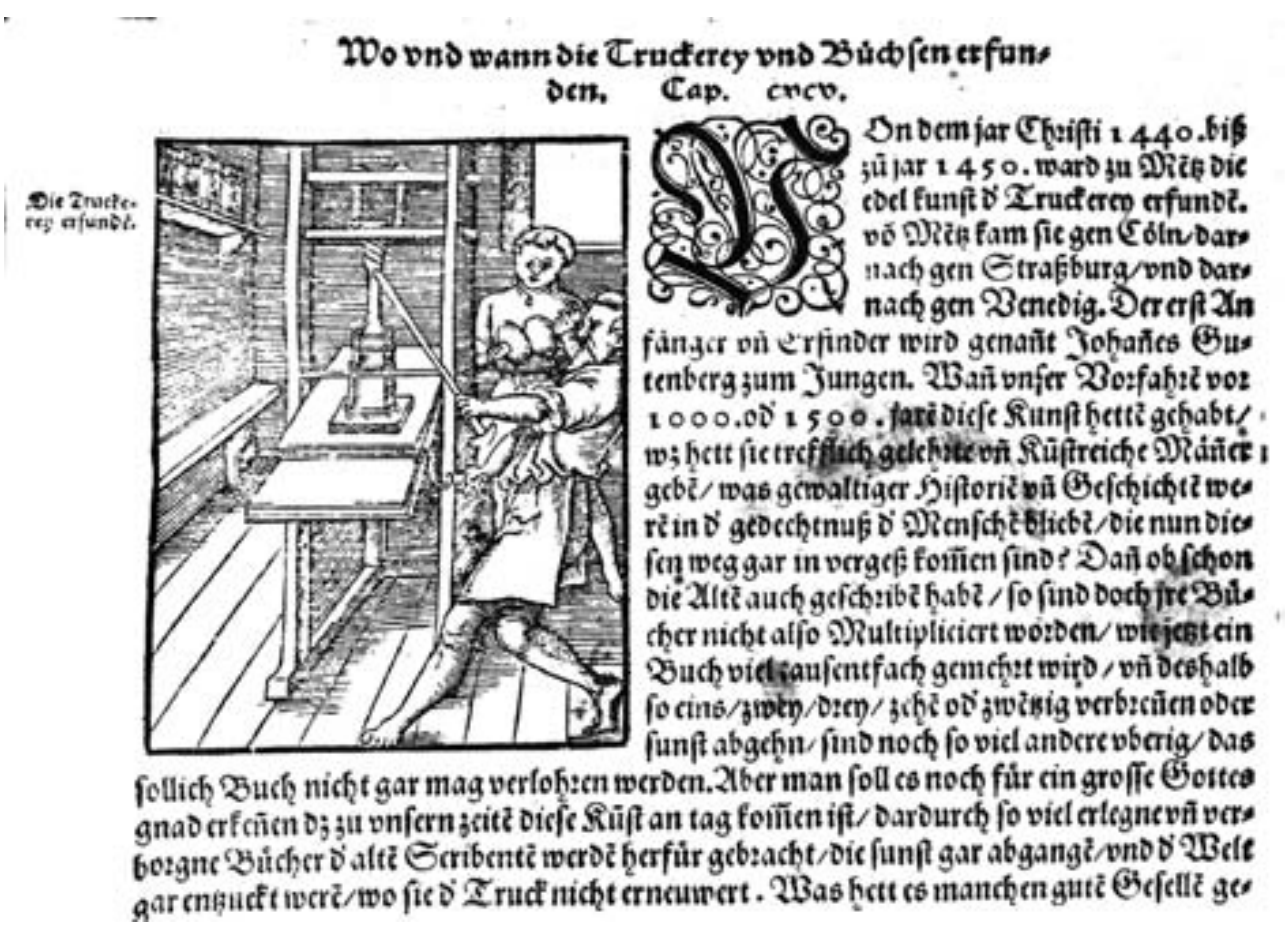

As Laurillard's arguments and as Brahe's example shows, the printing press rendered the preservative and transmissive function of dictation and note-taking redundant in a narrow, functional sense. Despite this, the lecture remained for quite some time the dictation of a text by older men and slavish note-taking by the young. In fact, the «revolution» of the printing press, and the attendant explosion of written material (albeit a slow ones, unfolding over two centuries or so) did not mark a particularly neat transition of any kind for lecturing and note-taking. As the rest of the world was veritably transformed by ready access to the Bible and other print material, dictation and note-taking persisted - despite some variance in practice - largely as if nothing had happened. As the Renaissance replaced God with man in culture, and the Reformation exchanged the icon for the book in religion, the lecture retained its basic outlines. This persistence raises some questions: Are there reasons other than institutional inertia for the persistence of the lecture as dictation post-Gutenberg? And if the lecture is doing more than transmitting information in an early version of our own information explosion, what exactly is it doing? 
Although I return to these questions later, the Gutenberg revolution makes it clear that practices in the lecture hall are not to be understood primarily in terms of information. The abundance, scarcity or efficient transmission of information is not so much the concern. The significance and persistence of the lecture over its 800 year history, in other words, cannot be explained in the terms (information, its transmission) applied retroactively by Laurillard to the university's history. For if the lecture were a question of more efficient textual transmission replacing antiquated oral communicative forms, it wouldn't have been necessary to wait for radio, TV, DVD or Internet to render it redundant. The advent of the printing press alone should have clearly marked the end, or at least the beginning of the end, of the lecture.

The longevity of the lecture puts the theory of knowledge behind these types of argument into question. The lecture is not simply one way of communicating knowledge among many others, as if knowledge was only so much data, to be combined with the most efficient means of transmission as they become available. Knowledge is instead inextricably merged with pedagogical forms, and the nature of these forms is as much about culture as it is about informational function. In this paper, I show how knowledge is enacted and performed in the lecture, and this enactment and the knowledge brought to life with it, changes over time. When textual scarcity reinforced an understanding of knowledge as more a matter of recovery than discovery, the lecture was configured in terms of the authority of the textual sources from which this knowledge was recovered. The processes of dictation and notation ensured that the lecture did not stray far from this textual authority. Oral performance or speaking in the lecture hall was necessitated by and grounded in the authority of the text, not in the authority or charisma of the delivery or the speaker. Even though it was reinforced by textual scarcity that disappeared with the printing press, this conception of textually-grounded knowledge and its enactment through dictation persisted long after the era of Gutenberg. Conceiving of knowledge apart from the authority and the book seems to have been as difficult in the medieval and early modern period as it is for us today to conceive of it apart from, information and its circulation. And just as the view of knowledge as textual authority was reinforced by the scarcity of the book in the middle ages, our current view of knowledge is authorized by the many technologies and practices of circulation and transmission that have become part of our everyday lives.

\section{The Lecture as Authorial Performance}

The shift from the dictation of an authoritative text to the various forms that the lecture has taken today did not occur in a clear or steady progression, or through a one or more epochal changes. But aspects of this shift can be traced through the rise of what are known as glosses and commentary in the early modern period. 
At the time of the manuscript, explanatory notes were written and copied into the margins of an authoritative text, assisting the lecturer in his explanation or commentary of a given passage. «In the beginning», as the Catholic Encyclopaedia notes, «masters noted down on their own copies... a few words by way of résumé, and as a help in their lectures» (Boudinhon 1909, n.p.) Later, glosses themselves would be considered authoritative, allowing a professor to "read' an exemplar already provided with an authorized 'gloss' which aided interpretation and itself became an object of commentary» (Verger 2000, 836). Glosses in this sense facilitated a move away from slavish dictation in the lecture, enabling the gradual emergence of different forms of commentary as ways of mediating between the traditional textual record, and the contemporary reader and his audience. Clark indicates a gradual shift from linear dictation to more unfettered commentary, saying that by the middle of the seventeenth century - again despite great variance in practice - the two were competing for dominance:

A 1642 lecture plan for the Jesuit philosophy faculty at Ingolstadt, for example, set an ideal...the first half hour of each lecture was to be for dictation and the second half hour for glosses and exegesis. Many early modern lectures seem to have become chaotic commentaries, or remained readings aloud, dictations page by page of a textbook. $(2006,83)$

Clark goes on to say that out of concerns for educational quality, the subsequent century saw a number of governments outlawing dictation altogether. "The eighteenth», Clark continues, "appears to be the century when dictation was first stopped, even if only erratically at first» $(2006,85)$. In other words, it is only some 300 years after the invention of print that a number of its functional attributes, are decisively integrated into the lecture. Clark goes on to say that one place and one person in particular marked a radical break with the dictated medieval lecture or sermon:

[It is in] the 1790's in the University of Jena [that Johann Gottlieb] Fichte became one of the first German professors who began officially lecturing without a set text... Fichte and other Romantics began lecturing on their own work without any pretense that that they were glossing a text or recapitulating a tradition... Departure from an actual or even virtual textbook as a basis for lecturing constituted the ultimate break with the sermon [or medieval lecture]. (410)

Fichte was a German idealist, a romantic philosopher, a landmark university administrator, and by all accounts, an outstanding public speaker. As a lecturer, 
he was characterized by his fellow romantics Goethe and Hegel as "extraordinary» and «rapturous.» The theologian Friedrich Schleiermacher, also the founder of hermeneutics as a method of interpretation, recognized Fichte's «splendid gift of clarity», but dismissed his «rhetoric» as only serving purposes of «fomentation» and «defamation.» It is reported that Fichte could lecture from a complete text as if he were speaking freely, that he could also speak fluently and at length from a single page of notes. He mocked those professors who could only «recite what lies printed on the page for all to see» (Fichte, as quoted in Kittler 1992, 155). In a 1794 lecture «concerning the difference between the spirit and the letter within philosophy», Fichte himself says that his principle concern is not what «is printed in books for us to read», but rather, "what has stirred and transformed our spirit» (207). Correspondingly, the lecture for Fichte was not about the authority of the book, but about the spirit which he wished would enliven the audience just as it enlivens the speaker: "... the wish with which I conclude today's lecture», Fichte says, «is that ... from time to time I can succeed in scattering in your souls fiery sparks which will arouse and stir them» (198-199).

Coming to expression in Fichte's hopes to stir the souls of his audience is a radically new way of understanding knowledge, one that implies a new relationship between text and speech in the context of the lecture. It is the speaker and his own words and ideas that are important. The value of these words and ideas, moreover, is understood in terms of their effect, like Fichte's, on his contemporary audience. As Clark explains,

Fichte and other Romantics began lecturing on their own work, without any pretense that they were glossing a text or recapitulating a tradition. ... In Romantic Jena and elsewhere, the cathedra [or podium] became a locus where one created knowledge, became a site of the new, radical stress on spontaneity, creativity and originality. ... a new relation between the Romantic «l» pontificating from the cathedra and the academic chorus [or audience began to emerge]. (410)

The lecture, in short, was no longer about the authority of the text, it is about the authority of the lecturer. The lecturer, in other words, is not a conduit for a tradition received from the past; nor is his or her task even a kind of commentary on this tradition. The medieval practice of interchangeable lecturers reading from the same authoritative texts loses its meaning and value. What is instead meaningful and valuable is one lecturer speaking his mind and standing as the authentic origin of his speech - as the author of his spoken thoughts and words.

Also seeing Fichte's example as «epochal», media theorist Friedrich Kittler describes Fichte and his Romantic colleague as enacting a specifically hermeneutic 
epistemological and mediatic configuration. As an explicit «method» to be used for interpretation or understanding, hermeneutics applies primarily to the text, but what is ultimately most important for hermeneutics is the spirit, rather than the letter. As the originator of hermeneutics as a formal area of study, Schleiermacher described it as a process of recovering to spirit what might otherwise be lost to the letter. Describing thought itself as a kind of inner speaking that is externalized in talking or writing, hermeneutics for Schleiermacher represents a kind of reversal of this externalization process. Every "act of understanding», Schleiermacher asserts, «is the inversion of a speech-act (Akt des Redens), during which the thought which was the basis of the speech must become conscious» $(1998,7)$. Meaning has its origin in the spirit of the speaker; it is temporarily externalized and enacted through speech, and it finally returns to the inner speech in the minds or spirits of audience members. The written text, or even grammar and rhetoric are all important for Schleiermacher, but they have value only insofar as they are interpreted or brought to life as thought. The text or written words (and to a lesser extent, speech itself) are only so many supports or prompts to realize and sustain the life of the spirit, or more modestly, of understanding and meaning. ${ }^{4}$

For similar reasons, the texts of both the speaker and the note-taker in the lecture hall are important only insofar as they capture and enable the creativity and originality of the speaker. Whether the lecture is a lively rendition of a verbatim transcript, or an extemporization based on a series of talking points, or delivered entirely "off the cuff», what counts is its authenticity. Student note taking, similarly, is not valued as a means of creating a verbatim record of a recitation, but becomes more a question of capturing the creativity and originality of the speaker --which sometimes was not recorded in any other form. The notes of students form the basis for some of the pivotal works of $20^{\text {th }}$ century theory and philosophy, as is the case for Ferdinand de Saussure, Ludwig Wittgenstein and Jacques Lacan.

For similar reasons, the texts of both the speaker and the note-taker in the lecture hall are important only insofar as they capture and enable the creativity and originality of the speaker. Whether the lecture is a lively rendition of a verbatim transcript, or an extemporization based on a series of talking points, or delivered entirely "off the cuff», what counts is its authenticity. Student note taking, similarly, is not valued as a means of creating a verbatim record of a recitation, but becomes more a question of capturing the creativity and originality of the speaker --which sometimes was not recorded in any other form. The notes of students form the

4 It appears that the pedagogical innovation of Fichte and his fellow Romantics took some time to reach American shores. John Dewey writes in 1891 of «the introduction of the lecture system» as gradually doing away with «recitation» and «vicious methods of rote study» (1969, 147; emphasis in original). He also envisions the «mediatic» evolution of this pedagogical form as taking place through "an increasing use of the printing press in preparing outlines, syllabuses, selections from authorities, etc. ... giv[ing] us a cross between the seminary [i.e. seminar] and recitation methods» (147). 
basis for some of the pivotal works of $20^{\text {th }}$ century theory and philosophy, as is the case for Ferdinand de Saussure, Ludwig Wittgenstein and Jacques Lacan.

\section{The Lecture as Dramaturgical Effect}

Speaking of the $20^{\text {th }}$ century of course takes us into a period where multiple technologies for projection, recording and transmission were added to text and speech in the mediatic mix of the lecture. The lectures of Michel Foucault at the Collège de France and those of physicist Richard Feynman at the California Institute of Technology, for example, are with us today thanks to audio and video recordings, rather to than faithful student note-taking. Radio and TV also extended the contemporaneous reach of the lecture, with famous examples of broadcasts including the Canadian Massey Lectures, as well as lectures by Theodore Adorno (despite his vociferous critique of mass media). At the same time, different kinds of projection media extended the content of the lecture beyond the spoken word. As one example, the overhead projector (like many other instructional innovations) was first applied to educational use during the Second World War by the US military, and was introduced in its canonical commercial form by 3M in the 1960's. Despite these changes, the lecture still, it seems, retains many of its epistemological traits and media combinations from Fichte's time. Perhaps the most significant difference is simply in the way these are articulated. This is illustrated by sociologist Erving Goffman's chapter on "The Lecture» in his Forms of Talk (1981). Originally delivered at the University of Michigan in 1976 as the Katz-Newcomb Memorial Lecture, Goffman's text provides a kind of secularized update of earlier idealist and romantic accounts of the lecture as an almost Pentecostal propagation of spirit. The uneasy relation between the "dead» letter and the animating force of speech reappears in Goffman, as does the related issue of the authenticity of the speaker as the origin of his or her own words. But these are all given a contemporary twist: In place of souls, spirits, minds, inner speech and thoughts, Goffman makes use of his principle contribution to sociology. This is his idea that any one person is an amalgam of multiple selves, an idea that today is familiar from the opposition of the «inner child» and the «adult self.» Except that the lecture, for Goffman, involves selves of a rather different nature, involving primarily the «textual» «dramaturgical» and «self-as-animator.» According to Goffman, the «whole» self is constituted as a kind of "dramatic effect arising from a [given] scene» (1959, p.252) with different selves emerging in different situations and moments. Instead of «fiery sparks» of thought and understanding, Goffman focuses on «talk» and its potential to be extemporaneous or "fresh.» Speaking of «the multiple senses in which the self of the speaker can appear» in the lecture (173), Goffman says that one particular self will inevitably be most important: 
At the apparent center will be the textual self, that is, the sense of the person that seems to stand behind the textual statements made and which incidentally gives these statements authority. Typically this is a self of relatively long standing, one the speaker was involved in long before the current occasion of talk. This is the self that others will cite as the author of various publications, recognize as the holder of various positions, and so forth.... And he is seen as the "principal», namely, someone who believes personally in what is being said and takes the position that is implied in the remarks. $(173)^{5}$

The textual self is responsible for the content of the lecture rather than for its delivery or its form. As Goffman puts it, this textual self is one that «can be displayed entirely through the printable aspects of words[, as] an emanation from the text itself. According to Goffman, it exists alongside a second self, which one might call the "embodied self» (although Goffman does not give it a name himself). This self is physically present in the lecture, and sometimes obtrusive, when as Goffman says, it would clear its throat or take an occasional drink of water. A third self involved in the lecture is the "Self-as-animator:» "the person [that] can be identified as the talking machine, the thing that sound comes out of» (167). It is that is responsible for enacting the lecture. This last manifestation of the self «that is intimately responsive to the current situation», venturing clearly beyond the text, for example, in remarks offered as asides, or in the context of openings and closings. The self-as-animator, in these instances, takes over from the textual self, and is itself the source of its own speech or content: «In the case of fresh talk, the text is formulated by the animator from moment to moment, or at least from clause to clause» (171).

Although he does not say it explicitly, the goal for the lecturer for Goffman is in effect a kind of combination or collapse of the textual self and the self-as-animator (while keeping the stumbling, throat clearing physical self in check). The self that is addressing and responsive to the occasion should be indistinguishable from the self that is supported and sustained by the text. This is achieved, according to Goffman, through a particular way of combining media. It is done by leveraging and aligning text and speech, or written and oral forms in very specific ways. Goffman outlines three ways of aligning these two media that were common in his day:

Goffman is taking as his paradigmatic example the kind of «invited» guest lecture that he himself was giving at the University of Michigan. This is one in which the speaker's credentials are often enumerated in his or her introduction, and are often known in advance in general terms by the audience. As we shall see below however, speaker and text, presence and substance remain central to the classroom lecture as well. 
In our society we recognize three main modes of animating spoken words: memorization, aloud reading (such as I had been doing up to now), and fresh talk. In the case of fresh talk, the text is formulated by the animator from moment to moment, or at least from clause to clause. Fresh talk is perhaps the general ideal and (with the assistance of notes) quite common....[Still] a great number of lectures (because of my incompetence, not including this one) depend upon a fresh-talk illusion. (171; only last emphasis added)

Goffman makes explicit what is implicit in Schleiermacher's notion of the hermeneutic "speech act», and in Fichte's emphatic differentiation of letter and spirit: Namely, that the ideal for the lecture is the successful creation of an illusion. Parts of the lecture may be memorized, but in a long-standing tradition, academic lectures are generally read aloud. And in reading aloud, what the lecturer strives to create is the illusion of spontaneity and extemporaneity. The speaker is in this way able to appear as a conduit between his own thoughts and those of the audience. As Schleiermacher or Fichte might put it, it is through the illusion of lively reading or delivery of the "dead letter» that the speaker to bring to life in the audience the thought which was the basis of the speech in the first place.

Fichte's ability to speak freely from both notes and a verbatim text-once seen as a gift worthy of special notice by his illustrious contemporaries-is later portrayed by Goffman as a general ideal, something that should be the goal of every effective speaker. «A great number of lectures» as Goffman says, "depend on a fresh-talk illusion» (172). The take place through a performance or act, a kind of sleight of hand. But at the same time, it is obviously not an act of magic. Goffman makes this clear by saying: "Your effective speaker is someone who has written his reading text in the spoken register; he has tied himself in advance to his upcoming audience with a typewriter ribbon» (190).

It is media, in this case the typewriter and typewritten word, which help make the fresh talk illusion a widespread phenomenon. The lecturer is to use these skilfully and methodically to craft, check and revise her lecture well in advance of its delivery, to ensure that her delivery appears as direct, responsive and even as spontaneous as possible. Today, Goffman's typewriter and ribbon have given way to a panoply of devices and media technologies, from a word-processor and printer, to PowerPoint with its speakers notes and bulleted lists. In the case of a podcast or videocast lecture like a TED Talk or Kahn Academy presentation, this range of media and bag of tricks is greatly enlarged, extending from careful audio and video editing, through to teleprompting techniques or overdubbing. 


\section{The Future of an Illusion}

Why does all of this matter for education? This account of the history of the lecture from the medieval cathedra to the fresh talk illusion highlights both continuities and changes in pedagogical practice in higher education. It suggests that the persistence of the lecture as a pedagogical form is not simply a matter of inertia and tradition, but that it is due to its flexibility and adaptability in response to changes in media and technology, as well as culture and epistemology. In fact, it would probably be more accurate to say that the lecture co-evolved with these larger developments, with its changes in the performance and meaning of the lecture helping to support and provide direction for developments in culture, as was the case with Fichte's speeches and Schleiermacher's hermeneutics. Not only does this way of understanding the lecture explain its persistence over its 800 year history, it also augments and reinforces ways of understanding the characteristics of good pedagogical practice. It provides a way of explaining what is important in this type of practice, and for predicting - or at least providing evidence for imagining - how it might change in response to future technological developments.

To speak first of pedagogical practice, the idea that the lecture is primarily about tying oneself to one's "audience with a typewriter ribbon», about using available media technologies or techniques that are described colourfully but consistently in terms of vitality, action or animation is central: Studies of effective lecturing or "how to" publications on the lecture are full of suggestions on how to achieve these effects, on how to bring a body of knowledge alive in the mind of the student audience. Aside from the most pragmatic and cognitive aspects (e.g. asking the lecturer to be prepared, and to structure but vary his or her presentations), these publications focus on the "self-as-animator», on fresh talk, on ways of arousing and stirring the attention and thought processes of one's listeners as a hermeneutic speech act. Consider for example these point form recommendations from "Lecturing to Large Groups», a chapter in A Handbook for Teaching and Learning in Higher Education (Morton 2009). Lecturers, the author says, should work to:

- share their passion and enthusiasm for the subject by telling students why they are personally interested in this topic. Where possible, this could be a link to their personal research;

- link the lecture to some current news or activity

- use relevant and current examples to illustrate the point;

- ... draw on the students' experiences;

- use rhetorical questions to encourage students to keep on track;

- use live links to the web to demonstrate currency of the material being presented. (60) 
To put this in the language of Fichte and Goffmann, it is clear that these recommendations are not about the textual self, about the dead letters prepared well in advance of the lecture. They are instead about the aside and the extemporization, about the illusion of fresh talk or the kind of fluid rendition of a complete or partial text that someone like Fichte was able to perform. It the sense of performing the "speech act» that Schleiermacher sees as essential to understanding: "the thought which was the basis of the speech must become conscious» in the audience in terms of their own thoughts and concerns.

Another way to put this would be to say that the effective lecture is an interpretive, hermeneutic exercise, in the sense of the term provided by Schleiermacher and hermeneuticians coming after him. It enacts and confirms the hermeneutic conception of knowledge as meaning or understanding circulating through a «speech act» - rather than authorizing the medieval conception of textual authority or even the modern view of knowledge as information to be stored, processed and transmitted. Hans-Georg Gadamer, a twentieth century hermeneutician, provides an updated account of knowledge as an act of interpretation, and of its relationship to oral and written media. «Interpretation», Gadamer says, «is performed by spoken language» $(2004,362)$. «Reading the text» by speaking it, he continues, is «the highest task of understanding» (392). And through this hermeneutic act of the lecture, he concludes, «written tradition is brought back ... into the living present of conversation» (362). The lecture, in short, transforms the artefact of the text into an event - an event in which the text is brought into conversational relationship with the audience and with the present.

Understanding the lecture in terms of a specifically hermeneutic way of knowing and communicating brings me to the conclusion of this paper - and from matters of practice to questions of theory. On the basis of this paper's analysis of the mediatic history of the lecture, it is possible to derive a set of general observations concerning the relationship between different media technologies in pedagogical contexts. First, this analysis has shown shows how the logic of mediatic and technological change in education is not successive but cumulative. Pedagogical forms that are rooted in orality such as the lecture are not simply done away with because new media develop that are supposedly superior or more efficient. McLuhan was in this sense wrong to insist that the «sheer quantity of information conveyed» by new media, on its own, would render the school "an obsolete detention home.» Instead of being replaced or rendered obsolete, the lecture with its oral roots is complemented, augmented and reconfigured through changes in textual technologies. The printing press gradually freed the lecture from the need to simply preserve information, and enabled it to increasingly reflect the position of the individual lecturer, as well as the living present of the audience. The subsequent introduction of audio, video, and visual aids for the lecture 
(overhead projectors, PowerPoint, even teleprompters) further enhanced the lecture's possibilities. These technologies have been increasingly arrayed around the lecturer and the lecture in support of her and her lecturing performance. They sustain and reinforce the illusion of the lecturer being the authentic origin of her own words. The role of related technologies in broadcasting and podcasting the lecture are similarly cumulative and complementary in their effect. This accumulation and augmentation, moreover, occurs not through a logic that reflects the indifferent operation of laws of necessity and maximal efficiency, but the more rounded contours of historical and cultural change.

The idea that change in media occurs through gradual, culturally-mediated accumulation rather than abrupt succession implies that individual innovations in media are not in themselves decisive. What is more important than individual media is the relation between different media forms and practices. The lecture takes its shape through its position at the intersection of oral and written forms, being first manifest as dictation and manuscript reproduction, then as authorial performance and finally as a dramaturgical effect that relies on textual and other media. Speaking of the last of these, Goffman points out that this dramatic effect can be realized by exploiting three possible ways of aligning text and spoken word: as memorization, as reading aloud and as (more or less) free talk. The options, Goffman is saying, are about how the oral and written are connected and configured. Of course, today there are more options with PowerPoint's speaker's notes and other software and hardware technologies developed in support of the lecture.

The relationships between writing and speech, and also between visual and audio media instantiated in the contemporary lecture, are fraught with tension and contradiction. This begins with the fact that the lecture is never simply oral, although in its modern form, it constantly seeks to give this illusion. It is the illusion of pure orality. These tensions are only increased, with video and audio foregrounding the non-textual, and PowerPoint and Smartboards (for example) providing ways of highlighting text --with both basic types of media (oral and textual) offering new ways to refine and heighten the sleight of hand that underlies the modern lecture. These relationships embody different epistemologies or beliefs about knowledge. They begin with text-as-authority; this gradually gives way to self-as-source. But despite this shift, the text still retains some of its authority, meaning that the ability of the lecturer must conceal but not in fact erase or do away with the power of this authority.

Given recent developments in these areas, the future bodes well for the illusion that we know of as the lecture. The dynamic and multimedial mix provided by the Web presents many possibilities for the lecture that can confirm its current - and longstanding - function of creating a living present for conversation. It does so not only by capturing the lecturer as performer and animator in audio and video, 
but by providing new and varied ways of inserting this performance into a living present. The lecturer in a TED talk, for example, is not only able to perform for the live audience at the occasion of the talk itself; his or her lecture is also situated in a quasi-conversational context when it is embedded in YouTube or elsewhere on the Web, surrounded with viewer comments and related videos. There is the promise of more elaborate technical aids for the lecturer, in terms of new presentation tools such as Elluminate Live, Voicethread, Adobe Captivate or Prezi. Combined with these and other technologies, the live lecture is open to new forms of what Goffman (and others) refer to as «backchannel» and more conversational participation. This can be accomplished, for example, through twitter, with this backchannel communication projected behind the speaker for an instantaneous conversational effect. The future of this illusion, in other words, is bright.

\section{References}

Blair, Ann. 2008. «Student manuscript and the textbook.» In Scholarly Knowledge: Textbooks in Early Modern Europe, ed. Emidio Campi, Simone de Angelis, Anja-Silvia Goeing and Anthony T. Grafton, 39-73. Geneva: Droz.

Böhme, Jeanette. 2006. Schule am Ende der Buchkultur: Medientheoretische Begründungen schulischer Bildungsarchitekturen. Bad Heilbrunn: Klinkhardt.

Boudinhon, Auguste. 1909. "Glosses, Glossaries, Glossarists.»In The Catholic Encyclopedia. New York: Robert Appleton Company. http://www.newadvent .org/cathen/06588a.htm.

Brent, Doug. 2005. "Teaching as performance in the electronic classroom.» First Monday 10 (4). http://firstmonday.org/issues/issue10_4/brent/index.html.

Briggs, Asa and Peter Burke. 2009. A Social History of the Media: From Gutenberg to the Internet. Third Edition. Cambridge, MA: Plity.

Clark, William. 2006. Academic Charisma and the Origins of the Research University. Chicago: University of Chicago Press.

Dewey, John. 1969. «Lectures vs. Recitations: A Symposium.» In The Early Works of John Dewey: 1882-1898, ed. Jo-Ann Boydston, 147. Carbondale IL: Southern Illinois UP.

Eisenstein, Elizabeth L. 1997. The Printing Press as an Agent of Change: Communications and Cultural Transformations in Early-Modern Europe. Cambridge: Cambridge U.P.

Franzel, Sean. 2010. «The Lecture: A Case Study in the Intermediality of Academic Instruction.» In Media Transatlantic: Media Theory in North America and German-Speaking Europe, ed. Norm Friesen and Richard Cavell, 35-36. Conference Program available at: http://www.mediatrans.ca/final_conference _program.pdf. 
Goffman, Erving. 1959. The Presentation of Self in Everyday Life. New York: Doubleday Anchor.

Goffman, Erving. 1981. On the Lecture: Forms of Talk. Philadelphia: University of Pennsylvania Press.

Hajnal, István. 1954. L'Enseignement de l'écriture aux universités médiévales. Budapest: Académie des Sciences de Hongrie.

Jarvis, Jeff. 2010. This is Bullshit. http://www.youtube.com/watch?v=rTOLkm5hNNU. Jones, Steve E. 2007. "Reflections on the lecture: outmoded medium or instrument of inspiration?» Journal of Further and Higher Education 31 (4): 397-406.

Kittler, Friedrich. 1990. Discourse Networks, 1800/1900. Stanford, CA: Stanford University Press.

Laurillard, Diana. 1993. Rethinking University Teaching: a framework for the effective use of educational technology. London: Routledge.

Laurillard, Diana. 2002. Rethinking University Teaching: a framework for the effective use of educational technology, 2nd edition. London: Routledge.

McLuhan, Marshall. 1960a. "Classroom without Walls.» In Explorations in Communication, ed. Edmund Carpenter and Marshall McLuhan, 1-3. Boston: Beacon Press.

McLuhan, Marshall. 1960b. «Five Sovereign Fingers Tax the Breath.»In Explorations in Communication, ed. Edmund Carpenter and Marshall McLuhan, 207-208. Boston: Beacon Press.

McLuhan, Marshall. 1964. Understanding Media: The Extensions of Man. New York: McGraw Hill.

Morton, Ann. 2009. "Lecturing to Large Groups.» In A Handbook for Teaching and Learning in Higher Education, ed. Heather Fry, Steve Ketteridge and StephanieMarshall, 58-71. London: Routledge.

Ong, Walter J. 1982. Orality and Literacy: The Technologizing of the Word. London: Routledge.

Schleiermacher, Friedrich D.E. 1998. Hermeneutics and Criticism and Other Writings. Ed. Andrew Bowie. Cambridge: Cambridge University Press.

Verger, J. 2000. «Lecture.» In Encyclopedia of the Middle Ages, Vol. 2, ed. Richard Barrie Dobson, 836. London: Routledge.

Wieruszowski, Helene. 1966. The Medieval University. Princeton: Van Nostrand. 